\title{
Cyclopes and Giants: From Homer's Odyssey to contemporary genetic diagnosis
}

\author{
Georgios K. Markantes, ${ }^{1}$ Anastasia Theodoropoulou, ${ }^{1}$ Anastasia K. Armeni, ${ }^{1}$ \\ Vasiliki Vasileiou, ${ }^{2}$ Constantine A. Stratakis, ${ }^{3}$ Neoklis A. Georgopoulos ${ }^{1}$
}

${ }^{1}$ Division of Reproductive Endocrinology, Department of Obstetrics and Gynecology, University of Patras Medical School, Patras; ${ }^{2} 1^{\text {st }}$ Department of Endocrinology, Diabetes Centre, "Alexandra" Hospital, Athens; Greece; ${ }^{3}$ Section on Endocrinology and Genetics, Eunice Kennedy Shriver National Institute of Child Health and Human Development, National Institutes of Health, Bethesda, USA

\section{GIANTS AND CYCLOPES}

Giant is a term used to describe a legendary humanlike being of great stature and strength. In Greek mythology, the giants Cyclopes rebelled against the Olympian Gods in a battle that ended in their final defeat, this resulting in Olympian sovereignty on earth. They initially appeared in Hesiod's Theogony as children of Gaia (Earth) and Uranus (Sky) and were described as powerful, savage and fearless beings with a single circular eye in the middle of their forehead. ${ }^{1}$

The most striking and best known story regarding Cyclopes ("Cyclopes" is the plural form of the singular "Cyclops") is that of Polyphemus, presented by Homer in his epic The Odyssey. In Book IX, Odysseus narrates to king Alcinous of Corfu and his court his

Key words: Acromegaly, Cyclops gigantism, Familial Isolated Pituitary Adenoma, Hemianopia, Homer, Odysseus, Pituitary adenoma

Address for correspondence:

Neoklis A. Georgopoulos, Department of Obstetrics and Gynecology, Division of Reproductive Endocrinology, University of Patras Medical School, Rio-26500, Greece; Tel.: 2610-999835, Fax: 2610-993854, E-mail: neoklisg@hol.gr Received: 15-03-2016, Accepted: 04-04-2016 adventures in the land of the Cyclops: Odysseus and his men were eventually captured by one of them, Polyphemus, son of Poseidon. Polyphemus, who was a cannibal, devoured several of Odysseus' men. In order to escape, they blinded Polyphemus by means of a huge pole with a burning tip after getting him drunk with sweet wine offered to him by Odysseus himself. What is particularly interesting in Homer's narration of the scene is that he - a master of detailed descriptions - does not at any point specifically state that Polyphemus had one single eye. On the other hand, this appears to be implied by the use of the singular "we bore the red hot beam into his eye", rather than the plural (eyes). ${ }^{2}$

And yet, another impression is given when Homer states that the steam produced from the Cyclops' burning eye scalded his eyelids and eyebrows (plural): “... so that the steam from the burning eyeball scalded his eyelids and eyebrows". Escaping from the cave, Odysseus and his companions had to face the attack of other Cyclopes who, responding to Polyphemus' screams for help, tried to sink Odysseus' ship as it was sailing away by hurling enormous rocks at it from the coastal hills. ${ }^{2}$

The above raises a very intriguing question: were the Cyclopes a product of pure imagination or could they represent gigantic humans who also had issues with their vision in real life? 


\section{MEDICAL DIFFERENTIAL DIAGNOSIS}

Extreme growth is defined as a height that is more than 2 standard deviations (SD) above the mean of the population. Overgrowth may be present at birth (macrosomia) and is usually due to constitutional factors; maternal diseases such as diabetes can also account for large size at birth. Overgrowth conditions such as Beckwith-Wiedemann or SimpsonGolabi-Behmel syndrome might also be responsible. In childhood or adolescence, a variety of endocrine (obesity, growth hormone [GH] excess, generalised lipodystrophy, glucocorticoid deficiency/resistance, sex hormone deficiency/insensitivity) and non-endocrine (sex chromosome aneuploidy, Marfan syndrome, homocystinuria, Neurofibromatosis type 1) conditions may be responsible for excessive growth. ${ }^{3-6}$

In the case of the Cyclopes, there are three core characteristics emerging from the textual evidence that could provide us with clues towards establishing a differential diagnosis.

First of all, they did not represent isolated cases of gigantic creatures; rather, they were described as being members of a family - brothers and/or relatives living in close proximity - by both Homer and Hesiod.

Second, their size is so enormous that is beyond human standards: Cyclopes are brothers of the Titans (gods) in Hesiod's Theogony and, though mortal, are depicted as oversized men by several orders of magnitude in The Odyssey.

Finally, they are characterised by the presence of one single circular eye, located in the middle of their forehead. However, as mentioned above, available descriptions of the Cyclopes are not definite regarding the number of their eyes. This therefore allows us to interpret the single circular eye as impaired "circular" vision. In other words, the Cyclopes could well have suffered from a severe impairment of their lateral vision in both directions, while their central vision would have been relatively normal. A lesion of the optic nerve prior to the chiasm would lead to vision impairment confined to the affected side, whereas a lesion after the chiasm would cause homonymous hemianopia (impaired vision of the right or left half of the visual field). However, a lesion affecting the optic chiasm results in bitemporal hemianopia, that is, loss of peripheral vision on both sides with central vision preservation.

Therefore, to medically interpret the case of Cyclopes, one must seek out a single cause leading to familial tall stature concurrent with vision impairment in the form of bitemporal hemianopia.

Of the aforementioned conditions, only those encompassing the oversecretion of GH prior to epiphyseal closure (leading to gigantism) as well as lesions in the area of the optic chiasm, such as neurofibromatosis and familial pituitary adenoma secreting $\mathrm{GH}$, could account for such a phenotype.

Neurofibromatosis type 1 (NF1) is an autosomal dominant disorder and its hallmark features include café au lait macules, freckling and neurofibromas. Optic pathway tumors are not infrequent in NF1 and usually present with impaired visual acuity and color vision or proptosis; however, they may involve the optic chiasm and cause bitemporal hemianopia. ${ }^{7}$ Hypothalamic involvement is possible in that instance and usually manifests as precocious or delayed puberty. ${ }^{8}$ Nevertheless, excess GH production and markedly increased stature has been reported in NF1 patients with optic tract tumors. ${ }^{9}$ Apparently, the concurrence of gigantism and bitemporal hemianopia is theoretically feasible in NF1. However, the possibility of this being a consistent finding in a whole series/family of patients is extremely small, given that in NF1 optic gliomas can occur in any part of the optic pathway and those affecting the chiasm are not the commonest.

A sizeable pituitary tumor may result in bitemporal hemianopia due to the close proximity of the pituitary gland to the optic chiasm. Furthermore, if this tumor is an adenoma overproducing GH that appeared before epiphyseal closure, the patient will also present with extreme growth. Thus, a condition responsible for the familial appearance of GH secreting pituitary adenomas might provide the link between the myth of the Cyclopes and reality.

The existence of individuals of extraordinary height is so compelling that it has engaged the interest of the scientific community throughout the centuries, with numerous cases having been reported. ${ }^{10}$ However, archaeological findings compatible with extreme growth in ancient skeletons are extremely rare. In 
fact, the first documentation of gigantism in a complete skeleton of the Roman Era was only recently published. ${ }^{11}$ Another case was recently encountered by one of our team at a Roman cemetery close to today's Serbian-Romanian border. ${ }^{12}$

Today, acromegaly is a well understood clinical entity caused by GH hypersecretion that leads to Insulin-Like Growth Factor 1 (IGF1) hyperproduction by the liver, resulting in the signs, symptoms and complications of the disease. In almost every instance (>98\% of cases), a pituitary adenoma overproducing GH is the cause of acromegaly..$^{13}$ The vast majority of pituitary adenomas occur sporadically. All the same, familial cases are increasingly being recognised, with a recent estimate being that up to $5 \%$ of such tumors are familial in origin. Familial pituitary adenomas may be part of the well-recognised syndromes of Multiple Endocrine Neoplasia Type 1 (MEN1) or Carney Complex (CC). Nevertheless, several families with members suffering from isolated pituitary tumors (lacking the clinical and genetic characteristics of the aforementioned syndromes) have been identified. The term Familial Isolated Pituitary Adenoma (FIPA) is used to describe this novel entity. In addition, more recently a defect on the X-chromosome leading to isolated gigantism was described; this and/or FIPA may be apposite conditions to consider for the diagnosis of the Cyclopes. ${ }^{14}$

FIPA is an autosomal dominant disease with low penetrance, representing approximately $2 \%$ of all pituitary adenomas. It is defined as the presence of pituitary adenomas in two or more related members per kindred, in the absence of clinical features or mutations associated with MEN1 or CC. More than 200 families with over 500 affected individuals have so far been described in the literature..$^{15}$ Within the same family, patients may have the same (homogenous FIPA) or different (heterogeneous FIPA) pituitary tumor type. The adenoma subtypes in FIPA patients include prolactinoma $37.5 \%$, somatotropinoma $35 \%$, non-functioning adenomas $14.5 \%$, somatoprolactinomas $6.4 \%$, Cushing disease $2.9 \%$, gonadotropinomas $2 \%$, plurihormonal tumors $1.2 \%$ and thyrotropinomas $0.5 \%$. FIPA patients are diagnosed 4 to 6 years earlier than patients with sporadic pituitary adenomas and usually have more aggressive tumors. In particular, somatotropinomas appear at an earlier age and are larger at diagnosis of FIPA than in the general population. ${ }^{16}$

The genetic basis of FIPA was unknown until 2006 when a Finnish group identified germline mutations in the AIP (aryl hydrocarbon receptor interacting protein) gene in several families segregating acromegaly and prolactinomas. ${ }^{17}$ AIP belongs to the family of tetratricopeptide repeat (TPR) domain-containing proteins. The TPR domains mediate intra- and intermolecular interactions in many proteins. Inactivating mutations in AIP predispose to tumor formation by leading to loss of inhibition of cAMP synthesis via alteration in the function of an inhibitory G-protein. In AIPrelated tumors, heterozygous germline mutations are associated with loss of heterozygosity ( $\mathrm{LOH}$ ) due to a "second hit" at the level of tumor DNA. This biallelic inactivation of AIP at the tumor level has led to the assumption that AIP acts as a tumor suppressor. ${ }^{17}$

To date, about 70 different germline AIP mutations have been identified; no somatic AIP mutations have been found in pituitary tumors. AIP mutations account for only a minority (about 20\%) of FIPA kindreds, suggesting that the genetic basis of FIPA has only partially been revealed. ${ }^{15}$

In FIPA patients bearing AIP mutations somatotropinomas and prolactinomas are very frequent, making up $90 \%$ of cases. In particular, acromegaly patients with AIP mutations present at a younger age, suffer from larger, more frequently invasive tumors, have higher GH levels and show worse response to treatment. Gigantism is also significantly more common in the setting of AIP mutations and may be considered as a characteristic phenotypic feature of the disease. ${ }^{18}$

A novel syndrome of infant-onset pituitary gigantism with a severe clinical phenotype was very recently reported for the first time by Trivellin et al. The authors have named it X-linked acro-gigantism (X-LAG), as it is caused by microduplications on chromosome Xq26.3, encompassing the gene GPR101. GPR101, which encodes a G-protein-coupled receptor, was overexpressed in patients' pituitary lesions. ${ }^{14}$ Most cases described so far are sporadic, but familial ones also exist. Given the early onset and severe clinical presentation of the disease in these patients, GPR101 might be considered as a promising candidate gene to explain cases of AIP mutation-negative patients with isolated gigantism. 
As for the case under review, familial gigantism in the context of an aggressive pituitary somatotropinoma compressing the optic chiasm due to a mutation either in AIP or GPR101 seems to be the most likely culprit behind the presumed phenotype of the Cyclopes. We consider FIPA or X-LAG far more plausible causes than MEN1 or CC, as in the latter pituitary tumors, and particularly somatotropinomas, are rare (affecting less than $10 \%$ of patients) and usually appear after the second decade of life, rendering the possibility of gigantism fairly remote..$^{19,20}$

It is noteworthy that the above approach to the myth of Cyclops is not unique. Other authors have suggested alternative explanations. Bazopoulou-Kyrkanidou proposed that the Cyclopes were individuals suffering from cyclopia, a congenital malformation characterised by the presence of a single eye. ${ }^{21}$ Cyclopia is the most severe form of holoprosencephaly (HPE), which is defined as an inadequate or absent midline division of the developing forebrain into the cerebral hemispheres. HPE and cyclopia are etiologically heterogeneous, resulting from chromosomal defects (trisomies, triploidy), gene mutations (involving extracellular signalling networks such as Sonic Hedgehog, etc.) as well as teratogen exposure. ${ }^{22}$ However, cyclopia has never been associated with extreme growth and familial clustering of cases is extremely rare.

In conclusion, a rigorous review of the relevant ancient Greek literature in light of up-to-date scientific data strongly indicates that the Cyclopes could have been actual humans suffering from a rare and extraordinary disease rather than simply mythological creatures. Gigantism in the context of FIPA or X-LAG caused by mutations known or still to be discovered can, if left untreated, even nowadays create true giants.

\section{REFERENCES}

1. Hesiod 1914 Theogony. In: William Heinemann Ltd (eds), The Homeric Hymns and Homerica with an English Translation by Hugh G. Evelyn-White, Cambridge, MA., Harvard University Press, London; lines 139-150.

2. Homer, The Odyssey, Book IX, Translated by Samuel Butler, The Internet Classics Archive, http://classics. mit.edu/Homer/odyssey.9.ix.html.

3. Reiter EO, Rosenfeld RG 1998 Normal and aberrant growth. In: Wilson JD, Foster DW, Kronenberg HM,
Larsen PR (eds), Williams Textbook of Endocrinology, Saunders, Philadelphia; pp, 1427.

4. Garg A, 2004 Acquired and inherited lipodystrophies. N Engl J Med 350: 1220-1234.

5. Dietz HC, Cutting GR, Pyeritz RE, et al, 1991 Marfan syndrome caused by a recurrent de novo missense mutation in the fibrillin gene. Nature 352: 337-339.

6. Mudd SH, Skovby F, Levy HL, et al, 1985 The natural history of homocystinuria due to cystathionine betasynthase deficiency. Am J Hum Genet 37: 1-31.

7. Ferner RE, Huson SM, Thomas N, et al, 2007 Guidelines for the diagnosis and management of individuals with neurofibromatosis 1. J Med Genet 44: 81-88.

8. Carmi D, Shohat M, Metzker A, Dickerman Z, 1999 Growth, puberty, and endocrine functions in patients with sporadic or familial neurofibromatosis type 1: a longitudinal study. Pediatrics 103: 1257-1262.

9. Josefson J, Listernick R, Fangusaro JR, Charrow J, Habiby R, 2011 Growth hormone excess in children with neurofibromatosis type 1-associated and sporadic optic pathway tumors. J Pediatr 158: 433-436.

10. De Herder W, 2009 Acromegaly and gigantism in the medical literature. Case descriptions in the era before and the early years after the initial publication of Pierre Marie (1886). Pituitary 12: 236-244.

11. Minozzi S, Pantano W, Di Gennaro F, Fomaciari G, Catalano P, 2012 Pituitary Disease from the Past: A Rare Case of Gigantism in Skeletal Remains from the Roman Imperial Age. J Clin Endocrinol Metab 97: 4302-4303.

12. Stratakis CA, 2015 A giant? Think of genetics: growth hormone-producing adenomas in the young are almost always the result of genetic defects. Endocrine 50: 272-275.

13. Asa SL, Kovacs K, 1992 Pituitary pathology in acromegaly. Endocrinol Metab Clin North Am 21: 553-574.

14. Trivellin G, Daly AF, Faucz FR, et al, 2014 Gigantism and acromegaly due to Xq26 microduplications and GPR101 mutation. N Engl J Med 371: 2363-2374.

15. Beckers A, Aaltonen LA, Daly AF, Karhu A, 2013 Familial isolated pituitary adenomas (FIPA) and the pituitary adenoma predisposition due to mutations in the aryl hydrocarbon receptor interacting protein (AIP) gene. Endocr Rev 34: 239-277.

16. Beckers A, Daly AF, 2007 The clinical, pathological, and genetic features of familial isolated pituitary adenomas. Eur J Endocrinol 157: 371-382.

17. Vierimaa O, Georgitsi M, Lehtonen R, et al, 2006 Pituitary adenoma predisposition caused by germline mutations in the AIP gene. Science 312: 1228-1230.

18. Daly AF, Tichomirowa MA, Petrossians P, et al, 2010 Clinical characteristics and therapeutic responses in patients with germ-line AIP mutations and pituitary adenomas: an international collaborative study. J Clin Endocrinol Metab 95: E373-383.

19. Agarwal SK, 2014 Exploring the tumors of multiple endocrine neoplasia type 1 in mouse models for basic 
and preclinical studies. Int J Endocr Oncol 1: 153-161.

20. Stratakis CA, Kirschner LS, Carney JA, 2001 Clinical and molecular features of the Carney complex: diagnostic criteria and recommendations for patient evaluation. $\mathrm{J}$ Clin Endocrinol Metab 86: 4041-4046.

21. Bazopoulou-Kyrkanidou E, 2005 The cyclopes in Od- ysseus’ Apologos. Am J Med Genet A 138A: 190-192. 22. Petryk A, Graf D, Marcucio R, 2015 Holoprosencephaly: signalling interactions between the brain and the face, the environment and the genes, and the phenotypic variability in animal models and humans. Wiley Interdiscip Rev Dev Biol 4: 17-32. 